\section{Animal Genetics}

December 2007, Volume 38 Issue 6, Pages 560-568

http://dx.doi.org/10.1111/j.1365-2052.2007.01647.x

(c) 2007 Blackwell Publishing, Inc.
Archimer, archive institutionnelle de l'Ifremer http://www.ifremer.fr/docelec/

The definitive version is available at www.blackwell-synergy.com

\title{
A first generation genetic linkage map of the European flat oyster Ostrea edulis (L.) based on AFLP and microsatellite markers
}

\author{
D. Lallias $^{1,2}$, A.R. Beaumont ${ }^{2}$, C.S. Haley ${ }^{3}$, P. Boudry ${ }^{1}$, S. Heurtebise ${ }^{1}$ and S. Lapègue ${ }^{1, *}$ \\ ${ }^{1}$ Ifremer, Laboratoire Génétique et Pathologie, Ronce-les-bains, 17390 La Tremblade, France \\ ${ }^{2}$ School of Ocean Sciences, College of Natural Sciences, University of Wales, Bangor, Menai Bridge, \\ Gwynedd, LL59 5AB, United Kingdom \\ ${ }^{3}$ Roslin Institute, Roslin, Midlothian, EH25 9PS, United Kingdom
}

"Corresponding author: Sylvie Lapègue, Ifremer, Laboratoire Génétique et Pathologie, Ronce-lesbains, 17390 La Tremblade, France

Tel. (33) 546762631 Fax. (33) 546762611

e.mail address : slapegue@ifremer.fr

\begin{abstract}
:
This study presents the first genetic linkage map for the European flat oyster Ostrea edulis. AFLP and 20 microsatellite markers were genotyped in a three-generation pedigree comprised of 2 grandparents, 2 parents and 92 progeny. Chi-square goodness of fit tests revealed high segregation distortion, which was significant for $32.8 \%$ of markers. Sixteen microsatellites and 235 AFLPs (170 AFLPs type 1:1 and 65 AFLPs type 3:1) were used to build sex-specific linkage maps using CriMap software. The first parental map (P1) consisted of 104 markers grouped in nine linkage groups, spanning $471.2 \mathrm{cM}$ with an average spacing of $4.86 \mathrm{cM}$. The second parental map (P2) consisted of 117 markers grouped in ten linkage groups (which equals the haploid chromosome number), covering $450.0 \mathrm{cM}$ with an average spacing of $4.21 \mathrm{cM}$. The estimated coverage of the genome was $82.4 \%$ for the P1 map and $84.2 \%$ for the P2 map. Eight linkage groups that were probably homologous between the two parents contained the same microsatellites and 3:1 AFLPs (segregating through both parents). Distorted markers were not randomly distributed across the genome and tended to cluster in a few linkage groups. Sex-specific differences in recombination rates were evident. This first generation genetic linkage map for $O$. edulis represents a major step towards the mapping of QTL, such as resistance to bonamiasis, a parasitosis that has drastically decreased populations of flat oysters since the 1960's.
\end{abstract}

Keywords: genetic linkage map, flat oyster, Ostrea edulis, AFLP, microsatellite. 


\section{Introduction}

The European flat oyster or "native” oyster, Ostrea edulis, is endemic to the Atlantic and Mediterranean coasts of Europe. Natural populations are found in eastern North America from Maine to Rhode Island, following intentional introductions in the 1940’s and 1950’s (Jaziri 1990). O. edulis exhibits interesting reproductive characteristics such as sequential protandrous hermaphroditism with the possibility of changing sex several times in the same reproductive season and brooding of eggs and early larvae in the mantle cavity (Yonge 1960; Le Dantec \& Marteil 1976).

The flat oyster industry was of considerable economical importance in the 19th century in France and Britain (Neild 1995). Massive mortalities occurred around the turn

of the $20^{\text {th }}$ century from which the industry has never recovered. Oyster aquaculture production fell further from 30000 tons in 1970 to 6000 tons (FAO, 2006) because of two parasitic diseases, marteiliasis (due to Marteilia refringens) and bonamiasis (due to Bonamia ostreae).

Since 1985, Ifremer (French Research Institute for Exploitation of the Sea) has been undertaking a selective breeding programme for resistance to bonamiasis with the main aim of producing families of oysters tolerant to the protozoan parasite $B$. ostreae (Haplosporidian protist, Carnegie et al. 2000). A similar approach was also used in Ireland (Culloty et al. 2004). In France, two improved oyster strains (S85 and S89) were produced by individual selection in mass spawning progenies (Naciri-Graven et al. 1998) and represent a valuable genetic resource for QTL mapping of this trait. 
Genetic linkage maps have been established for almost all major aquaculturally important species, including tilapia (e.g. Agresti et al. 2000), catfish (e.g. Waldbieser et al. 2001), salmon (e.g. Moen et al. 2004), rainbow trout (e.g. Nichols et al. 2003), abalone (e.g. Baranski et al. 2006) and shrimps (e.g. Li et al. 2003). A few studies reported the construction of genetic maps in bivalves including oysters, in the Pacific oyster Crassostrea gigas (Hubert \& Hedgecock 2004; Li \& Guo 2004), the Eastern oyster Crassostrea virginica (Yu \& Guo 2003), the blue mussel (Lallias et al. in press) and the Zhikong scallop Chlamys farreri (Wang et al. 2004; Li et al. 2005; Wang et al. 2005). QTL have been mapped in a few shellfish species, including disease resistance in $C$. virginica (Yu \& Guo 2006) and production traits in the Kuruma prawn (Li et al. 2006). A genetic linkage map for the flat oyster is a first step towards the identification of QTL of resistance to bonamiasis and the eventual development of marker-assisted selection.

\title{
Material and methods
}

\author{
Mapping family
}

The first stage of the selective breeding programme initiated by Ifremer in 1985 consisted of the production of two improved oyster strains (S85 and S89) by mass selection (Naciri-Graven et al. 1998). Selection was applied both through inoculation tests (Mialhe et al. 1988) in an experimental hatchery and by field testing in natural conditions. In parallel to the selection programme, several generations of inbred lines have been produced since 1995. These inbred lines were initiated by crossing the selected oyster 
strain S89 and a wild-type oyster, followed by successive full-sib matings. A sixthgeneration inbred line, OELL2000-set2, has had zero mortality from bonamiasis in the field since 2000 .

The mapping family used in this study was initiated in 2003 by crossing a wildtype oyster (W102) and an oyster from the inbred line OELL2000-set 2 (L002-53). Two full-sibs from this F1 family were then crossed to make the mapping family (OE.F2.04.63). The mapping family consisted of two grand-parents (F0; L002-53 and W102), two parents (F1; 23-31 and 23-32) and 92 progeny (F2). The mapping family was sampled when the progeny were about 15 month old.

In order to achieve bi-parental crosses, oysters were held in pairs in small aquaria. Each aquarium was individually supplied with filtered sea water and the outlet pipe of each aquarium was placed above a $100 \mu$ m-mesh sieve for the collection of late larvae. It is not possible to non-destructively identify female oysters even when they are brooding so the respective sexes of the two F1 parents were not determined. The F1 parent 23-31 was referred to as "Parent 1" or "P1" and the F1 parent 23-32 as "Parent 2" or "P2".

\section{Genotyping}

DNA was extracted from gill tissue using a standard chloroform extraction followed by purification with the Wizard ${ }^{\circledR}$ DNA Clean-Up System (Promega) (Wilding et al. 2001). Quality and concentration of DNA of each sample was assessed using a spectrophotometer and by running a small amount on a $2 \%$ agarose gel. 
Twenty microsatellite markers selected from those developed by Naciri et al. (1995), Launey (1998), Morgan et al. (2000), Morgan \& Rogers (2001), Sobolewska et al. (2001) and Launey et al. (2002) were amplified by PCR according to the authors' protocols. Markers informative in the parents were genotyped across the full family. AFLP analysis was performed using a modified version of Vos et al. (1995) following Wilding et al. (2001), but digestion and ligation were achieved in the same mix by incubating for 16 hours at $16^{\circ} \mathrm{C}$. Sixty AFLP primer pairs were genotyped in the mapping family (Supplemental Table S1). Electrophoresis and data collection was carried out on an ABI 3100-Avant (Applied Biosystems). Electrophoresis parameters were set at injection for $15 \mathrm{~s}$ at $15 \mathrm{kV}$, running for $25 \mathrm{~min}$ at $15 \mathrm{kV}$ and $60^{\circ} \mathrm{C}$, with POP4 polymer. Data were analysed with GeneMapper® software version 3.7 and individuals were scored for the presence $[\mathrm{A}]$ or absence [a] of the amplified AFLP fragment (peak). A peakabsent marker phenotype was assumed to be the homozygote genotype $a a$.

\section{Distortion of segregation ratios}

Segregation distortion analysis was performed using $\chi^{2}$ goodness of fit statistical test between the F1 parents and the F2 progeny. For the codominant microsatellites, three types of segregation could be observed depending on the number of alleles present in the two parents: 1:1:1:1; 1:2:1 and 1:1 distributions. For the dominant AFLP markers, there were only two genotypic classes: presence or absence of the peak. Two types of segregation could be observed, either 1:1 (when only one of the two parents exhibited the peak) or 3:1 (when both parents exhibited the peak). Inference of AFLP genotypes from 
the phenotype (presence or absence of peak) allowed determination of the following AFLP transmissions:

- $\quad$ type I for which only one F0 parent and one F1 parent exhibited the peak; each phenotype could be assigned to a genotype ( $A a$ for presence of the peak or aa for absence of the peak) and the grand-parental and parental origins of AFLP alleles could be tracked without ambiguity (1:1 segregation type)

- $\quad$ type II for which both grand-parents were Aa and only one F1 parent exhibited the peak; each phenotype could be assigned to a genotype (Aa or $a a$ ) but it was not possible to assign the grand-parental origin of the $A$ allele (1:1 segregation type)

- $\quad$ type III for which only one F0 parent and the two F1 parents exhibited the peak; the presence of a peak in the F2 progeny led to an ambiguous genotype $A$ ? (either $A A$ or $A a$ ) but the grand-parental origin of the $A$ allele could be tracked (3:1 segregation type).

\section{Linkage analysis}

CriMap software (Green et al. 1990) was used for the construction of genetic linkage maps. First, the Two Point option was used to estimate recombination frequencies between each pair of markers for each of the two F1 parents, at a LOD score $\geq 3.0$. These two-point data were used to construct parent-specific linkage groups. The second step consisted of ordering markers within each linkage group using the Build command, with sequential incorporation of loci starting with the most informative pair of markers. The Fixed and All commands were used to add the unplaced markers after Build into the map, by decreasing order of informativeness. After the addition of a new marker to a sequence 
of ordered markers, the new order was tested against alternative order using the Flips command. Markers that led to an ambiguous map position (i.e. markers that had two or more alternative map positions with a small difference in their likelihood) were discarded from further analysis. Finally, the Chrompic command was used to display the number and location of recombinations on each chromosome, highlighting candidate data errors.

The mapping of 20 microsatellite markers and type III AFLPs (segregating through both Parent 1 and Parent 2) in the two parental genetic linkage maps P1 and P2 allowed the identification of probable homology groups. Homology groups were assumed when at least two markers (microsatellites and/or AFLPs) were linked in two linkage groups (P1 and P2) and when several markers in the same linkage group were common to both the P1 and P2 maps. Indeed, some common markers were linked but could not be assigned to the two parental maps because they had ambiguous map positions and were therefore discarded.

Genome size and coverage

Average marker spacing of each map was calculated by dividing the total length of the map by the number of intervals. The average marker spacing for each linkage group was calculated by dividing the length of each linkage group by the number of intervals on that linkage group. The expected length of the genome was estimated using method 4 of Chakravarti et al. (1991). Genome coverage estimates were determined by dividing the observed genome length by the expected length of the genome. 
Recombination frequency

Differences in recombination frequencies between the two parents were estimated using G-tests of independence that compared parental and recombinant genotypes for each parent for each pair of linked markers (with LOD score > 3.0).

\section{Results}

Segregation distortion

High segregation distortion was evident in the mapping family. Only $25 \%$ of the microsatellites (4 out of 16 informative markers: Oe1/47, Oe3/37, Oedu.HA21 and Oedu.B11) appeared to segregate according to Mendelian rules. Sixty one percent of the 1:1 AFLPs (107 out of 175 markers) and 92\% of the 3:1 AFLPs (65 out of 71 markers) exhibited Mendelian segregation. Overall, 69\% of the AFLP markers (172 out of 246 markers) were considered to have Mendelian inheritance. The high percentage of Mendelian 3:1 AFLPs compared to the 1:1 AFLPs was probably due to the fact that selection of 3:1 markers was based on a preliminary scoring of 48 F2 individuals after which highly distorted 3:1 AFLPs were discarded. In total, 16 microsatellites and 235 AFLPs (170 AFLPs type 1:1 and 65 Mendelian AFLPs type 3:1) for a total of 251 markers were included in the final linkage analysis. Distorted microsatellites and 1:1 AFLPs were included in the analysis after mapping the non-distorted markers. 
Parent-specific linkage maps

The P1 genetic linkage map was based on 16 microsatellites and 145 AFLPs segregating in this parent. The AFLPs consisted of 71 markers of type I (31 from L002-53, 40 from W102), 9 of type II and 65 of type III (37 from L002-53, 28 from W102). The resulting map consisted of 104 markers (64.6\% of available markers), comprising 14 microsatellites (87.5\%), 62 type I AFLPs (87.3\%), 7 type II AFLPs (77.8\%) and 21 type III AFLPs (32.3\%). Nine linkage groups were set up for the P1 map covering $471.2 \mathrm{cM}$ (Figure 1). The sizes of the linkage groups ranged from $23.6 \mathrm{cM}$ to $95.8 \mathrm{cM}$. The number of markers per linkage group varied from 4 to 22. The average distance between two loci ranged from $3.16 \mathrm{cM}\left(\mathrm{P} 1 \_3\right)$ to $10.1 \mathrm{cM}\left(\mathrm{P} 1 \_8\right)$, with an average spacing of $4.86 \mathrm{cM}$. The largest interval varied from 9.7 cM (P1_3) to 35.3 cM (P1_4) (Table 1). The observed map length was $471.2 \mathrm{cM}$ for the P1 map and the estimated genome length was 571.7 cM. The observed coverage was therefore $82.4 \%$ for the P1 map.

The P2 genetic linkage map was based on 16 microsatellites and 154 AFLPs segregating in this parent. The AFLPs consisted of 84 markers of type I (38 from L00253, 46 from W102), 5 of type II and 65 of type III (37 from L002-53, 28 from W102). The resulting map consisted of 117 markers (76.0\% of available markers), comprising 14 microsatellites (87.5\%), 76 type I AFLPs (90.5\%), 5 type II AFLPs (100\%) and 22 type III AFLPs (33.8\%). Ten linkage groups were set up for the P2 map covering $450.0 \mathrm{cM}$ (Figure 1). The sizes of the linkage groups ranged from $11.9 \mathrm{cM}$ to $77.7 \mathrm{cM}$. The number of markers per linkage group varied from 2 to 24 . The average distance between two loci ranged from 1.34 cM (P2_11) to 26.1 cM (P2_10), with an average spacing of $4.21 \mathrm{cM}$. 
The largest interval varied from 10.5 cM (P2_1) to 26.1 cM (P2_10) (Table 1). For the P2 map, the observed map was $450 \mathrm{cM}$ and the estimated genome length $575.8 \mathrm{cM}$. The observed coverage was $84.2 \%$ for the P2 map.

Eight probable homology groups were identified. No homology group was found for P1_9, P2_10 and P2_11. Two pairs of homology groups (P1_2 and P2_2; P1_8 and P2_8) were found based on linkage of several markers that were mapped in only one of the two parental maps: P1_2 and P2_2 have 4 common markers that could be mapped only in P2_2; P1_8 and P2_8 have 2 common markers that could be mapped only in P2_8 (Table 1 and Figure 1). Comparison of orders of markers between the two parental maps was possible for the six homology groups in which common markers were mapped in both P1 and P2 maps. Marker order seemed conserved for most homology groups. The greatest discrepancy occurred for group 1 where five microsatellites were not in the same order in the two maps. The lengths of homology groups 3 and 5 were similar between the P1 and P2 maps but in most cases there was a discrepancy in homology group lengths between the two maps, particularly for group 1 and group 6 (Figure 1).

Distorted AFLP markers showed non-random distribution or clustering in both genetic maps (P1 and P2). In the P1 map, the 30 mapped distorted AFLPs (type 1:1) were mainly located on four linkage groups, P1_2 (containing 12 aa homozygote deficiency markers in a 35 cM segment), P1_5 (containing 3 aa homozygote deficiency markers and 1 aa homozygote excess marker), P1_6 (containing 6 aa homozygote deficiency markers in a 38 cM segment) and P1_9 (containing 2 markers with aa homozygote deficiency and 2 with aa homozygote excess). In addition, four other groups contained each only one distorted marker showing aa homozygote deficiency: P1_1, P1_4, P1_7 and P1_8. In the 
P2 map, the 26 mapped distorted AFLPs were concentrated on three linkage groups, P2_1 (containing 9 aa homozygote deficiency markers and 1 aa homozygote excess marker), P2_11 (containing 5 markers with $a a$ homozygote deficiency and 5 with $a a$ homozygote excess in a 5 cM segment) and P2_7 (containing 4 aa homozygote deficiency markers in a 16 cM segment). In addition, two other groups, P2_2 and P2_6, each contained one distorted marker showing aa homozygote deficiency (Figure 1).

Distribution of markers

The assumption of a random distribution of AFLP markers in the genome was tested by Spearman correlation coefficients and chi-square test for departure from a Poisson distribution following Barreneche et al. (1998). Spearman correlation coefficients $\left(\mathrm{r}_{\mathrm{s}}\right)$ between genetic length and number of markers per group were 0.85 for the parent 1 $\left(\mathrm{u}_{\mathrm{c}}=2.40, \mathrm{p}<0.05\right)$ and $0.61\left(\mathrm{u}_{\mathrm{c}}=1.84, \mathrm{p}>0.05\right)$ for Parent 2. Therefore, AFLP markers were generally randomly distributed in the linkage groups of the P1 map but not randomly distributed in the P2 map, due to significant clustering of markers. Observed and expected distributions of AFLPs were compared for $20 \mathrm{cM}$ intervals in both P1 and P2 maps. The mean of the Poisson distribution was 4.2 for P1 and 4.95 for P2. No significant departure from the Poisson distribution was observed for Parent $1\left(\chi^{2}=3.1,6\right.$ d.f., $\mathrm{p}=0.796$ ). However, this goodness-of-fit test was highly significant for Parent 2 $\left(\chi^{2}=81.04,13\right.$ d.f., $\left.\mathrm{p}=0.000\right)$, mostly due to three intervals of $20 \mathrm{cM}$ containing only one marker (large interval gaps remained to be filled in P2_4, P2_6 and P2_10) and to one interval of 20 cM containing 14 markers (high clustering in P2_11). 
Parent-specific recombination differences

Differences in recombination frequencies were observed between the two parents. Eighty six pairs of markers were segregating in both parents (17 pairs of microsatellites and 69 pairs of microsatellite/AFLP). Forty four pairs of markers showed statistically different recombination frequencies between Parent 1 and Parent 2, 12 of these were associated with higher recombination in Parent 2 and 32 with higher recombination in Parent 1 (Figure 2).

\section{Discussion}

Mapping family and experimental design

The mapping family consisted of a three-generation pedigree (grand-parents, parents and offspring) that did not come from truly inbred lines (homozygous for all loci), but from a cross between a $6^{\text {th }}$ generation inbred line and a wild oyster. This mating scheme is unusual for a mapping family in a shellfish species. Indeed, the classical mating schemes in experimental populations where inbred lines are available generally involve the analysis of either backcross or F2 progeny. Some mapping panels reported in the literature consist of three-generation pedigrees of backcross families (Naruse et al. 2000; Sakamoto et al. 2000; Li \& Guo 2004), or F2 families (Shimoda et al. 1999; Li et al. 2003). Other mapping panels consisted of two generation pedigrees (parents and 
offspring) (Coimbra et al. 2003, Lallias et al. in press). However, when studying natural populations, or when inbred lines are not available, individuals can be taken from the population, genotyped and mated in pairs to yield a number of full-sib families. In a particular family, any pair of segregating loci will represent either an F2 (if both parents are heterozygous for the pair of markers) or a backcross (if only one parent is heterozygous whereas the other is homozygous) (Kearsey \& Pooni 1998). This strategy has been used in several studies (Waldbieser et al. 2001; Yu \& Guo 2003; Wang et al. 2005; Li et al. 2006; Lallias et al. in press) and is the most commonly used experimental design in shellfish species.

However, in the context of QTL mapping, a three-generation pedigree was chosen for our mapping family in O. edulis. This experimental design proved to be efficient for the mapping of microsatellites (87.5\% mapped in both parents) and type I AFLPs (87.3\% mapped in P1 and 90.5\% mapped in P2). However, as expected according to the informativeness of the markers (Ritter et al. 1990), the mapping of type III AFLPs (3:1 segregation) in a F2-type family was less powerful because only $32.3 \%$ and $33.8 \%$ were mapped in the two parental maps.

Segregation distortion

High segregation distortion was evident in our mapping family of O. edulis. Overall, $32.8 \%$ of the markers were distorted with microsatellites being commonly so (75\%) and AFLPs much less so (31\%). The range of segregation distortion reported in this study was similar or slightly higher than that reported in another oyster species, C. gigas: $31 \%$ 
with allozymes (McGoldrick \& Hedgecock 1997), 20.9\% with microsatellites (Launey \& Hedgecock 2001), and 26.9\% with AFLPs (Li \& Guo 2004). In our study, the high proportion (85.1\%) of distorted AFLP markers that showed an aa homozygote deficiency could be explained by a high genetic load that has previously been reported in bivalves (McGoldrick \& Hedgecock 1997; Bierne et al. 1998; Launey \& Hedgecock 2001). The mapping family came from crossing into a selected oyster strain that had been through a strong population bottleneck with a small effective number of breeders (Launey et al. 2001). In addition, the mapping family originated from six generations of full-sib matings that would certainly have undergone some inbreeding depression. Therefore, assuming that purging of deleterious genes by full-sib crosses was not complete by the $6^{\text {th }}$ generation, it is probable that the high segregation distortion observed was due to linkage of markers with lethal or deleterious genes in the recessive state.

The mapping of distorted markers may help to understand the distribution of deleterious recessive genes in the genome. Indeed, Yu \& Guo (2003) reported in C. virginica the clustering of six distorted markers in an area spanning $5 \mathrm{cM}$, which could potentially correspond to the presence of a deleterious gene nearby. In the same way, $\mathrm{Li}$ \& Guo (2004) reported the mapping of at least four major deleterious recessive genes in the female map of the Pacific oyster, highlighted by the clustering of markers with segregation distortion in the same direction. In the rainbow trout (Oncorhynchus mykiss) map, large regions of linkage groups contained blocks of distorted markers that could be linked to sub-lethal genes (Young et al. 1998). In our study, distorted markers tended to cluster on specific linkage groups and sometimes to a small segment of a linkage group 
(Figure 1). These clusters of distorted markers could therefore correspond to the location of potential deleterious genes in O. edulis.

However, markers with aa homozygote deficiency and with aa homozygote excess could be found on the same linkage groups (P2_1, P1_5, P1_9 and P2_11; see Figure 1). With type I AFLP segregation, in which one grand-parent and one parent carries a DNA fragment, the grand-parental and parental origins of AFLP alleles could be tracked without ambiguity but not the pedigree. Indeed, consider the grand-parental cross $\mathrm{A}_{1} / \mathrm{a}_{1}$ by $\mathrm{a}_{2} / \mathrm{a}_{2}$, where the numbers are used to track pedigree. The two $\mathrm{F} 1$ parents have to be $A_{1} / a_{2}$ and $a_{1} / a_{2}$, so that the progeny are $A_{1} / a_{1}, A_{1} / a_{2}, a_{1} / a_{2}$, and $a_{2} / a_{2}$. Thus, $A a$ (markerpresence phenotype) and aa (marker-absent phenotype) progeny are each of two possible types, one of which is grand-parental and therefore potentially homozygous identical by descent (IBD) for a linked recessive deleterious mutation. Excesses of a homozygotes can still be attributable to IBD for a linked mutation. This is the likely explanation for the deficiency of $A a$ heterozygotes within a region of $A a$ excesses on P2_11 for example, all the more because the Aa grand-parent in these cases was L002-53, which has an elevated likelihood of being homozygous for a deleterious recessive mutation.

\section{Linkage map and genome coverage}

This study presents the first genetic linkage map for the European flat oyster O. edulis and the first linkage map in any flat oyster species. The genome coverage achieved in $O$. edulis was good, above $82 \%$, and compared favourably with the ones established in cupped oyster species which were in the range of 70-90\% depending on the study (Yu \& 
Guo 2003; Hubert \& Hedgecock 2004; Li \& Guo 2004). Moreover, the number of linkage groups in Parent 2 matched the haploid number of ten chromosomes in this species (Thiriot-Quiévreux \& Ayraud 1982; Thiriot-Quiévreux 1984) although only nine linkage groups could be clearly identified in Parent 1. This discrepancy for Parent 1 suggests that gaps remain to be filled and that more markers should be added to the maps for a better coverage of the genome. This was confirmed by the fact that only eight probable homology groups were found, and that no clear homology could be found for three linkage groups, P1_9, P2_10 and P2_11. Finally, some of the linkage groups consisted of only two markers or spanned a small genetic distance ( $<20 \mathrm{cM})$. Therefore, these groups may in fact belong to the same chromosome and may coalesce by adding more markers.

Recombination differences between the sexes

Our study reported higher recombination rates in the Parent 1 with 32 significant pairwise recombination rate differences (out of 44) compared with Parent 2 (12 out of 44 significant pairwise comparisons) (Figure 2). Unfortunately, because of the brooding behaviour of $O$. edulis the sex of our individual F1 oyster parents could not be determined. However, large sex-specific differences in recombination rates have been reported in several studies. Higher recombination rates in females were found in rainbow trout (Sakamoto et al. 2000), channel catfish (Waldbieser et al. 2001), zebrafish (Knapik et al. 1998), C. virginica (Yu \& Guo 2003), C. gigas (Hubert \& Hedgecock 2004) and P. monodon (Wilson et al. 2002). Therefore, these potential sex-specific differences in 
recombination rates in $O$. edulis should be confirmed and investigated further by mapping more markers.

Future uses

The development of genetic linkage maps is particularly useful for the mapping of QTLs and for marker-assisted selection (MAS). Several studies have highlighted the potential for marker assisted selection in breeding programmes in fisheries (Ward et al. 2000; Perry et al. 2001; Liu \& Cordes 2004). MAS has a huge potential in aquaculture breeding programme, especially for traits difficult to phenotype, but so far no successfully applied MAS has been reported in fish or shellfish species. Although disease resistance generally seems to have a low heritability in some species (Gjedrem 2000), it is nevertheless an ideal trait for the application of MAS, due to the economic significance of high survival in aquaculture. Moreover, MAS would reduce the time between generations of selection. Several studies have reported the location of QTLs for disease resistance in rainbow trout, based on the classical approach for QTL mapping using interval mapping, the ANOVA-based approach, or bulk segregant analysis (BSA) (Palti et al. 1999; Ozaki et al. 2001; Rodriguez et al. 2004). Disease resistance is of particular interest for the flat oyster that has suffered such a huge decline from parasitic diseases and MAS for disease resistance could be an important tool in the regeneration of oyster aquaculture. The $O$. edulis genetic map described here represents a first step towards the search for QTLs in this species. 


\section{Acknowledgements}

This work was funded by INTERREG IIIB (Atlantic Aquaculture Arc Group, AAAG) and received the support of the Marine Genomics Europe Network of Excellence through a one-month fellowship (Gender Action Plan). CSH acknowledges funding from the BBSRC. We thank one of the anonymous reviewers for useful comments and suggestions.

\section{References}

Agresti J.J., Seki S., Cnaani A., Poompuang S., Hallerman E.M., Umiel N., Hulata G., Gall G.A.E. \& May B. (2000) Breeding new strains of tilapia: development of an artificial center of origin and linkage map based on AFLP and microsatellite loci. Aquaculture 185, 43-56.

Baranski M., Loughnan S., Austin C.M. \& Robinson N. (2006) A microsatellite linkage map of the blacklip abalone, Haliotis rubra. Animal Genetics 37, 563-570.

Barreneche T., Bodenes C., Lexer C., Trontin J.-F., Fluch S., Streiff R., Plomion C., Roussel G., Steinkellner H., Burg K., Favre J.-M., Glössl J., Kremer A. (1998) A genetic linkage map of Quercus robur L. (pedunculate oak) based on RAPD, SCAR, microsatellite, minisatellite, isozyme and 5S rDNA markers. Theoretical and Applied Genetics 97, 1090-1103. 
Bierne N., Launey S., Naciri-Graven Y. \& Bonhomme F. (1998) Early effect of inbreeding as revealed by microsatellite analyses on Ostrea edulis larvae. Genetics 148, 1893-1906.

Carnegie R.B., Barber B.J., Culloty S.C., Figueras A.J. \& Distel D.L. (2000) Development of a PCR assay for detection of the oyster pathogen Bonamia ostreae and support for its inclusion in the Haplosporidia. Diseases of Aquatic Organisms 42, 199-206.

Chakravarti A., Lasher L.K. \& Reefer J.E. (1991) A maximum likelihood method for estimating genome length using genetic linkage data. Genetics 128, 175-182.

Coimbra M.R.M., Kobayashi K., Koretsugu S., Hasegawa O., Ohara E., Ozaki A., Sakamoto T., Naruse K. \& Okamoto N. (2003) A genetic linkage map of the Japanese flounder, Paralichthys olivaceus. Aquaculture 220, 203-218.

Culloty S.C., Cronin M.A. \& Mulcahy M.F. (2004) Potential resistance of a number of populations of the oyster Ostrea edulis to the parasite Bonamia ostreae. Aquaculture 237, 41-58.

Food and Agriculture Organization of the United Nations (FAO), 2006. FishStat, http://www.fao.org/fi/statist/FISOFT/FISHPLUS.asp.

Gjedrem T. (2000) Genetic improvement of cold-water fish species. Aquaculture Research 31, 25-33.

Green S., Falls K. \& Crooks S. (1990) Documentation for CRI-MAP v2.4. Washington University School of Medicine, St. Louis.

Hubert S. \& Hedgecock D. (2004) Linkage maps of microsatellite DNA markers for the Pacific oyster Crassostrea gigas. Genetics 168, 351-362. 
Jaziri H. (1990) Variations génétiques et structuration biogéographique chez un bivalve marin: l'huitre plate Ostrea edulis L. (PhD thesis). Montpellier, France, University of Montpellier II.

Kearsey M.J. \& Pooni H.S. (1998) The genetical analysis of quantitative traits, Cheltenham, Stanley Thornes.

Knapik E.W., Goodman A., Ekker M., Chevrette M., Delgado J., Neuhauss S., Shimoda N., Driever W., Fishman M.C. \& Jacob H.J. (1998) A microsatellite genetic linkage map for zebrafish (Danio rerio). Nature Genetics 18, 338-343.

Lallias D., Lapègue S., Hecquet C., Boudry P. \& Beaumont A.R. (2007) AFLP-based genetic linkage maps of the blue mussel (Mytilus edulis). Animal Genetics 38, 340349.

Launey S. (1998) Marqueurs microsatellites chez l'huître plate Ostrea edulis L. : caractérisation et applications à un programme de sélection pour une résistance au parasite Bonamia ostreae et à l'étude de populations naturelles. Thèse de doctorat. Institut national agronomique Paris Grignon.

Launey S., Barre M., Gerard A. \& Naciri-Graven Y. (2001) Population bottleneck and effective size in Bonamia ostreae-resistant populations of Ostrea edulis as inferred by microsatellite markers. Genetical Research 78, 259-270.

Launey S. \& Hedgecock D. (2001) High genetic load in the Pacific oyster Crassostrea gigas. Genetics 159, 255-265.

Launey S., Ledu C., Boudry P., Bonhomme F. \& Naciri-Graven Y. (2002) Geographic structure in the European flat oyster (Ostrea edulis L.) as revealed by microsatellite polymorphism. Journal of Heredity 93, 331-351. 
Le Dantec J. \& Marteil L. (1976) La reproduction des huitres. Revue des Travaux de l'Institut des Peches marines 40, 233-256.

Li L. \& Guo X. (2004) AFLP-based genetic linkage maps of the pacific oyster Crassostrea gigas Thunberg. Marine Biotechnology 6, 26-36.

Li L., Xiang J., Liu X., Zhang Y., Dong B. \& Zhang X. (2005) Construction of AFLPbased genetic linkage map for Zhikong scallop, Chlamys farreri Jones et Preston and mapping of sex-linked markers. Aquaculture 245, 63-73.

Li Y., Byrne K., Miggiano E., Whan V., Moore S., Keys S., Crocos P., Preston N. \& Lehnert S. (2003) Genetic mapping of the kuruma prawn Penaeus japonicus using AFLP markers. Aquaculture 219, 143-156.

Li Y., Dierens L., Byrne K., Miggiano E., Lehnert S., Preston N. \& Lyons R. (2006) QTL detection of production traits for the Kuruma prawn Penaeus japonicus (Bate) using AFLP markers. Aquaculture 258, 198-210.

Li Z., Li J., Wang Q., He Y., Liu P. (2006) AFLP-based genetic linkage map of marine shrimp Penaeus (Fenneropenaeus) chinensis. Aquaculture 261, 463-472.

Liu Z.J. \& Cordes J.F. (2004) DNA marker technologies and their applications in aquaculture genetics. Aquaculture 238, 1-37.

McGoldrick D.J. \& Hedgecock D. (1997) Fixation, segregation and linkage of allozyme loci in inbred families of the Pacific oyster Crassostrea gigas (Thunberg): implications for the causes of inbreeding depression. Genetics 146, 321-334.

Mialhe E., Bachere E., Chagot D. \& Grizel H. (1988) Isolation and purification of the protozoan Bonamia ostreae (Pichot et al. 1980), a parasite affecting the flat oyster Ostrea edulis L. Aquaculture 71, 293-299. 
Moen T., Hoyheim B., Munck H. \& Gomez-Raya L. (2004) A linkage map of Atlantic salmon (Salmo salar) reveals an uncommonly large difference in recombination rate between the sexes. Animal Genetics 35, 81-92.

Morgan T.S. \& Rogers A.D. (2001) Specificity and sensitivity of microsatellite markers for the identification of larvae. Marine Biology 139, 967-973.

Morgan T.S., Rogers A.D. \& Iyengar A. (2000) Novel microsatellite markers for the European oyster Ostrea edulis. Molecular Ecology 9, 495-497.

Naciri-Graven Y., Martin A.-G., Baud J.-P., Renault T. \& Gerard A. (1998) Selecting the flat oyster Ostrea edulis (L.) for survival when infected with the parasite Bonamia ostreae. Journal of Experimental Marine Biology and Ecology 224, 91-107.

Naciri Y., Vigouroux Y., Dallas J., Desmarais E., Delsert C. \& Bonhomme F. (1995) Identification and inheritance of (GA/TC)n and (AC/GT)n repeats in the European flat oyster Ostrea edulis (L.). Molecular Marine Biology and Biotechnology 4, 83-89.

Naruse K., Fukamachi S., Mitani H., Kondo M., Matsuoka T., Kondo S., Hanamura N., Morita Y., Hasegawa K., Nishigaki R., Shimada A., Wada H., Kusakabe T., Suzuki N., Kinoshita M., Kanamori A., Terado T., Kimura H., Nonaka M. \& Shima A. (2000) A detailed linkage map of medaka, Oryzias latipes: comparative genomics and genome evolution. Genetics 154, 1773-1784.

Neild R. (1995) The English, the French and the oyster, Quiller Press, London.

Nichols K.M., Young W.P., Danzmann R.G., Robison B.D., Rexroad C., Noakes M., Phillips R.B., Bentzen P., Spies I., Knudsen K., Allendorf F.W., Cunningham B.M., Brunelli J., Zhang H., Ristow S., Drew R., Brown K.H., Wheeler P.A. \& Thorgaard 
G.H. (2003) A consolidated linkage map for rainbow trout (Oncorhynchus mykiss). Animal Genetics 34, 102-115.

Ozaki A., Sakamoto T., Khoo S., Nakamura K., Coimbra M.R., Akutsu T. \& Okamoto N. (2001) Quantitative trait loci (QTLs) associated with resistance/susceptibility to infectious pancreatic necrosis virus (IPNV) in rainbow trout (Oncorhynchus mykiss). Molecular Genetics and Genomics 265, 23-31.

Palti Y., Parsons J.E. \& Thorgaard G.H. (1999) Identification of candidate DNA markers associated with IHN virus resistance in backcrosses of rainbow (Oncorhynchus mykiss) and cutthroat trout (O. clarki). Aquaculture 173, 81-94.

Perry G.M., Danzmann R.G., Ferguson M.M. \& Gibson J.P. (2001) Quantitative trait loci for upper thermal tolerance in outbred strains of rainbow trout (Oncorhynchus mykiss). Heredity 86, 333-341.

Ritter E., Gebhardt C. \& Salamini F. (1990) Estimation of recombination frequencies and construction of RFLP linkage maps in plants from crosses between heterozygous parents. Genetics 125, 645-654.

Rodriguez M.F., Lapatra S., Williams S., Famula T. \& May B. (2004) Genetic markers associated with resistance to infectious hematopoietic necrosis in rainbow and steelhead trout (Oncorhynchus mykiss) backcrosses. Aquaculture 241, 93-115.

Sakamoto T., Danzmann R.G., Gharbi K., Howard P., Ozaki A., Khoo S.K., Woram R.A., Okamoto N., Ferguson M.M., Holm L.E., Guyomard R. \& Hoyheim B. (2000) A microsatellite linkage map of rainbow trout (Oncorhynchus mykiss) characterized by large sex-specific differences in recombination rates. Genetics 155, 1331-1345. 
Shimoda N., Knapik E.W., Ziniti J., Sim C., Yamada E., Kaplan S., Jackson D., De Sauvage F., Jacob H. \& Fishman M.C. (1999) Zebrafish genetic map with 2000 microsatellite markers. Genomics 58, 219-232.

Sobolewska H., Beaumont A.R. \& Hamilton A. (2001) Dinucleotide microsatellites isolated from the European flat oyster, Ostrea edulis. Molecular Ecology Notes 1, 7980.

Thiriot-Quiévreux C. (1984) Analyse comparée des caryotypes d'ostreidae (Bivalvia). Cahiers de Biologie Marine 25, 407-418.

Thiriot-Quiévreux C. \& Ayraud N. (1982) Les caryotypes de quelques espèces de bivalves et de gastéropodes marins Marine Biology 70, 165-172.

Vos P., Hogers R., Bleeker M., Reijans M., Van De Lee T., Hornes M., Frijters A., Pot J., Peleman J., Kuiper M. \& Zabeau M. (1995) AFLP: a new technique for DNA fingerprinting. Nucleic Acids Research 23, 4407-4414.

Waldbieser G.C., Bosworth B.G., Nonneman D.J. \& Wolters W.R. (2001) A microsatellite-based genetic linkage map for channel catfish, Ictalurus punctatus. Genetics 158, 727-734.

Wang L., Song L., Chang Y., Xu W., Ni D. \& Guo X. (2005) A preliminary genetic map of Zhikong scallop (Chlamys farreri Jones et Preston 1904). Aquaculture Research 36, 643-653.

Wang S., Bao Z., Pan J., Zhang L., Yao B., Zhan A., Bi K. \& Zhang Q. (2004) AFLP linkage map of an intraspecific cross in Chlamys farreri. Journal of Shellfish Research 23, 491-499. 
Ward R.D., English L.J., Mcgoldrick D.J., Nell J.A. \& Thompson P.A. (2000) Genetic improvement of the Pacific oyster Crassostrea gigas (Thunberg) in Australia. Aquaculture Research 31, 35-44.

Wilding C.S., Butlin R.K. \& Grahame J. (2001) Differential gene exchange between parapatric morphs of Littorina saxatilis detected using AFLP markers. Journal of Evolutionary Biology 14, 611-619.

Wilson K., Li Y., Whan V., Lehnert S., Byrne K., Moore S., Pongsomboon S., Tassanakajon A., Rosenberg G., Ballment E., Fayazi Z., Swan J., Kenway M. \& Benzie J. (2002) Genetic mapping of the black tiger shrimp Penaeus monodon with amplified fragment length polymorphism. Aquaculture 204, 297-309.

Yonge C.M. (1960) Oysters, The New Naturalist, Collins, London, 209 p.

Young W.P., Wheeler P.A., Coryell V.H., Keim P. \& Thorgaard G.H. (1998) A detailed linkage map of rainbow trout produced using doubled haploids. Genetics 148, 839850.

Yu Z. \& Guo X. (2003) Genetic linkage map of the eastern oyster Crassostrea virginica Gmelin. Biological Bulletin 204, 327-338.

Yu Z. \& Guo X. (2006) Identification and mapping of disease-resistance QTLs in the eastern oyster, Crassostrea virginica Gmelin. Aquaculture 254, 160-170. 
Supplemental Table S1. Primer pairs used for scoring AFLPs, with their abbreviations.

\begin{tabular}{llllll}
\hline & E-CAG [A] & E-ACG [B] & E-AAC [C] & E-ACA [D] & E-ACT [E] \\
& FAM & HEX & FAM & NED & NED \\
\hline M-CGA [1] & A1 & B1 & C1 & D1 & E1 \\
M-CAA [2] & A2 & B2 & C2 & D2 & E2 \\
M-CTG [3] & A3 & B3 & C3 & D3 & E3 \\
M-CAT [4] & A4 & B4 & C4 & D4 & E4 \\
M-CTT [5] & A5 & B5 & C5 & D5 & E5 \\
M-ATC [6] & A6 & B6 & C6 & D6 & E6 \\
M-AGT [7] & A7 & B7 & C7 & D7 & E7 \\
M-CTC [8] & A8 & B8 & C8 & D8 & E8 \\
M-CTA [9] & A9 & B9 & C9 & D9 & E9 \\
M-CAC [10] & A10 & B10 & C10 & D10 & E10 \\
M-CAG [11] & A11 & B11 & C11 & D11 & E11 \\
M-CCT [12] & A12 & B12 & C12 & D12 & E12 \\
\hline
\end{tabular}

EcoRI primers (E-) are coded by [letters], and MseI primers (M-) are coded by [numbers]. The three letters following $\mathrm{E}$ - and $\mathrm{M}$ - refer to the three selective nucleotides added at the 3' end of the selective primers. EcoRI-selective primers were fluorescently 5' labelled with FAM, HEX or NED. 
Table 1. Statistics for homology linkage groups for the Parent 1 and Parent 2 genetic maps of the European flat oyster O. edulis.

\begin{tabular}{|c|c|c|c|c|c|c|c|c|c|}
\hline \multirow[b]{2}{*}{$\begin{array}{l}\text { Linkage } \\
\text { group }\end{array}$} & \multirow[b]{2}{*}{$\begin{array}{l}\text { Common } \\
\text { markers }\end{array}$} & \multicolumn{4}{|l|}{ Parent 1} & \multicolumn{4}{|l|}{ Parent 2} \\
\hline & & $\begin{array}{l}\text { Length } \\
\text { (cM) }\end{array}$ & $\begin{array}{l}\text { No. } \\
\text { markers }\end{array}$ & $\begin{array}{l}\text { Marker } \\
\text { spacing (cM) }\end{array}$ & $\begin{array}{l}\text { Largest } \\
\text { interval (cM) }\end{array}$ & $\begin{array}{l}\text { Length } \\
\text { (cM) }\end{array}$ & $\begin{array}{l}\text { No. } \\
\text { markers }\end{array}$ & $\begin{array}{l}\text { Marker } \\
\text { spacing (cM) }\end{array}$ & $\begin{array}{l}\text { Largest } \\
\text { interval (cM) }\end{array}$ \\
\hline 1 & $17(7)$ & 95.8 & 21 & 4.79 & 22.5 & 65.4 & 17 & 4.09 & 10.5 \\
\hline 2 & $4(4$ in $P 2)$ & 72.1 & 14 & 4.81 & 23.7 & 50.7 & 13 & 4.23 & 18.9 \\
\hline 3 & $7(6)$ & 66.4 & 22 & 3.16 & 9.7 & 68.8 & 24 & 2.99 & 17.8 \\
\hline 4 & $3(2)$ & 63.4 & 9 & 7.93 & 35.3 & 77.7 & 15 & 5.55 & 23.0 \\
\hline 5 & $1(1)$ & 50.0 & 11 & 5.00 & 11.8 & 45.8 & 11 & 4.58 & 14.2 \\
\hline 6 & $4(4)$ & 38.0 & 10 & 4.22 & 15.4 & 69.8 & 10 & 7.76 & 24.2 \\
\hline 7 & $7(2)$ & 31.6 & 6 & 6.32 & 18.1 & 16.4 & 6 & 3.28 & 12.1 \\
\hline 8 & 2 (2 in $\mathrm{P} 2)$ & 30.3 & 4 & 10.10 & 17.6 & 11.9 & 5 & 2.98 & 10.8 \\
\hline 9 & $0(0)$ & 23.6 & 7 & 3.93 & 11.4 & - & - & - & - \\
\hline 10 & $0(0)$ & - & - & - & - & 26.1 & 2 & 26.10 & 26.1 \\
\hline 11 & $0(0)$ & - & - & - & - & 17.4 & 14 & 1.34 & 11.0 \\
\hline Total & 45 (28) & 471.2 & 104 & 4.86 & 35.3 & 450.0 & 117 & 4.21 & 26.1 \\
\hline
\end{tabular}

In brackets are the number of common markers that were mapped in both P1 and P2 maps (some common markers were linked to a group but could not be mapped). 
Figure 1. Microsatellite and AFLP-based linkage maps of the flat oyster $O$. edulis in the mapping family OE.F2.04.63: P1 (23-31) and P2 (23-32) maps obtained with CriMap. AFLP markers are labelled with the primer pair name followed by the letter "f”" (for fragment) and a 3-digit fragment size in base pairs. Markers are indicated on the right and absolute positions on the left (in Kosambi cM). The segregation type (I, II or III; see text) and the direction of the segregation distortion: towards a deficit (-) or excess (+) of $a a$ homozygotes are included on the right of the AFLP locus. Lines between P1 and P2 groups indicate homologous positions, with common markers underlined.

Figure 2. OE.F2.04.63 Parent 1 versus Parent 2 recombination fractions for 86 pairs of markers segregating from both parents. Recombination fractions $(\theta)$ between two microsatellite markers (diamond) or between one AFLP marker and one microsatellite (square) were plotted. Open symbols are cases in which $\theta$ was statistically homogeneous between the two parents; solid symbols are cases in which $\theta$ was significantly heterogeneous between the two parents $(\mathrm{p}<0.05)$. 


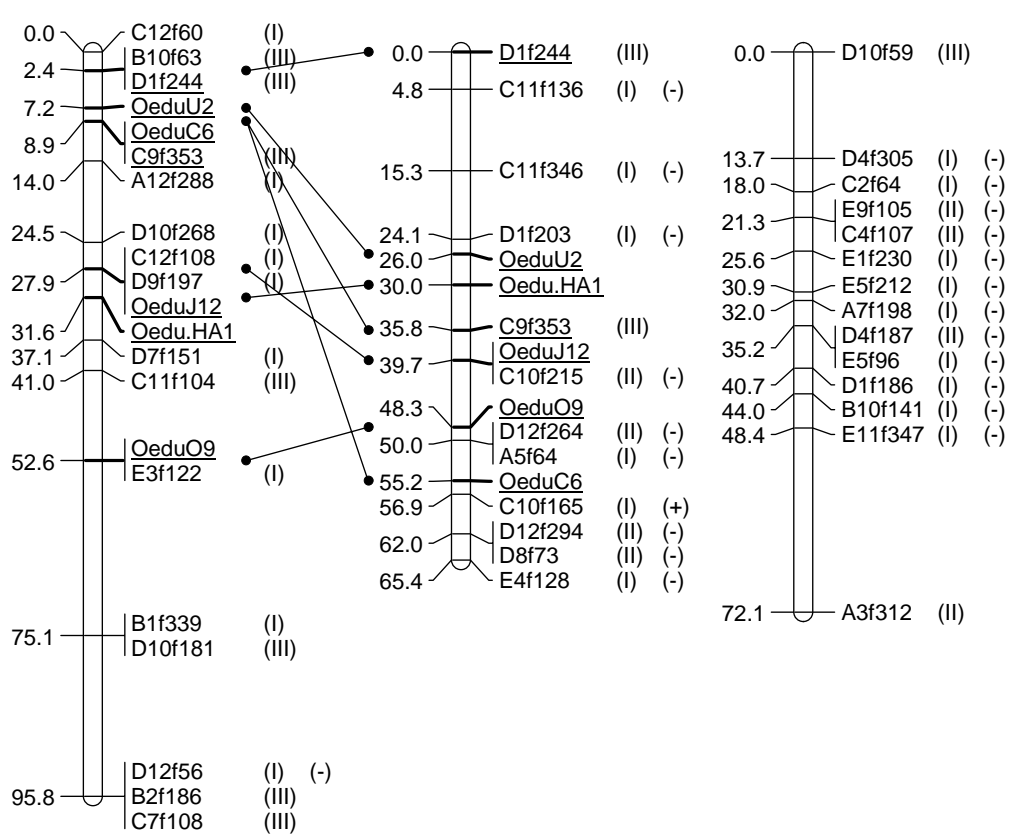

P1_5

P2_5

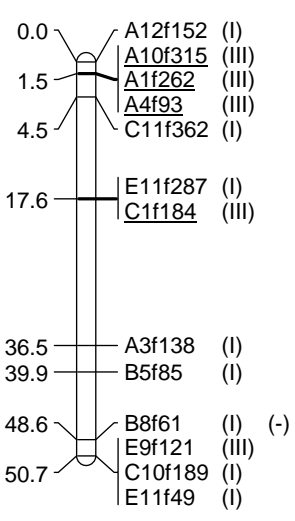

P1_7
P2 7

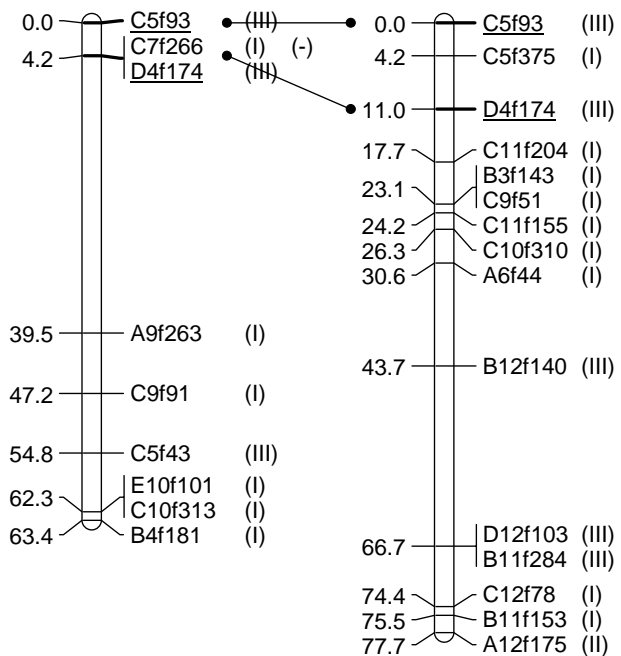

P1_8

P2 8
P2_6

P1_6

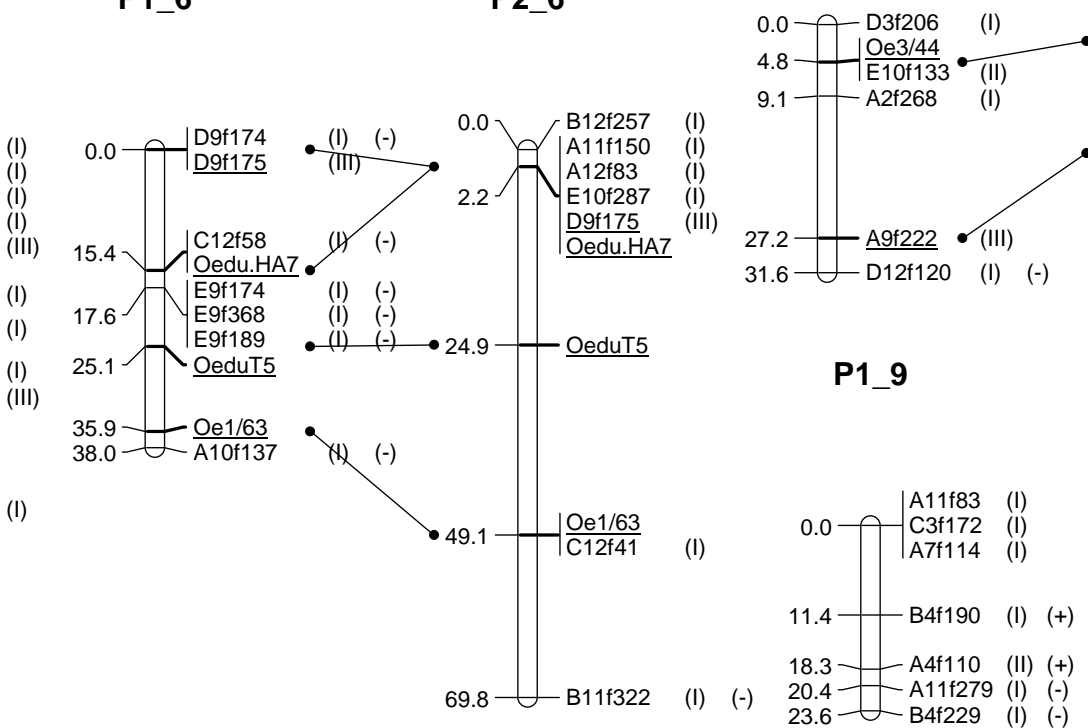

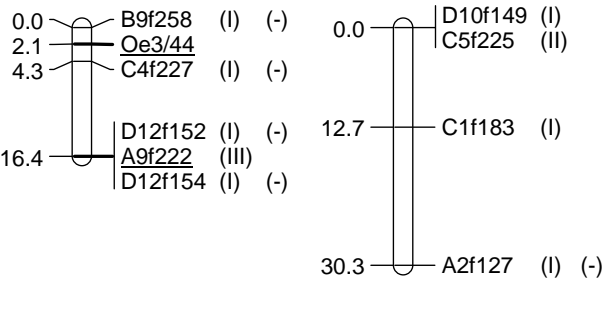

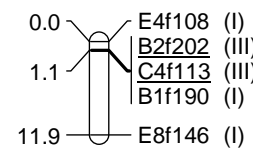

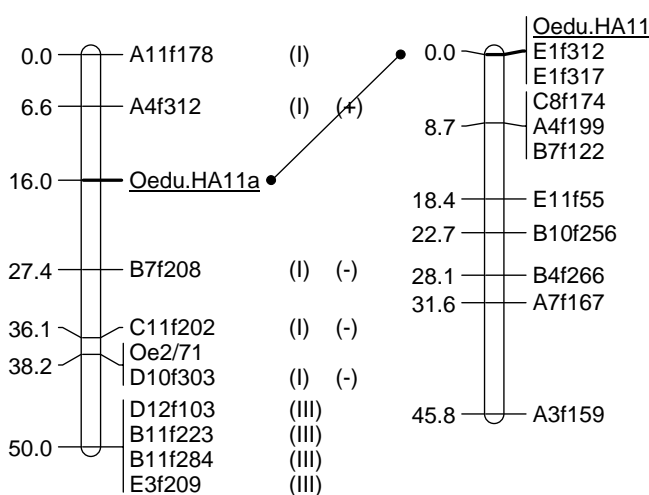

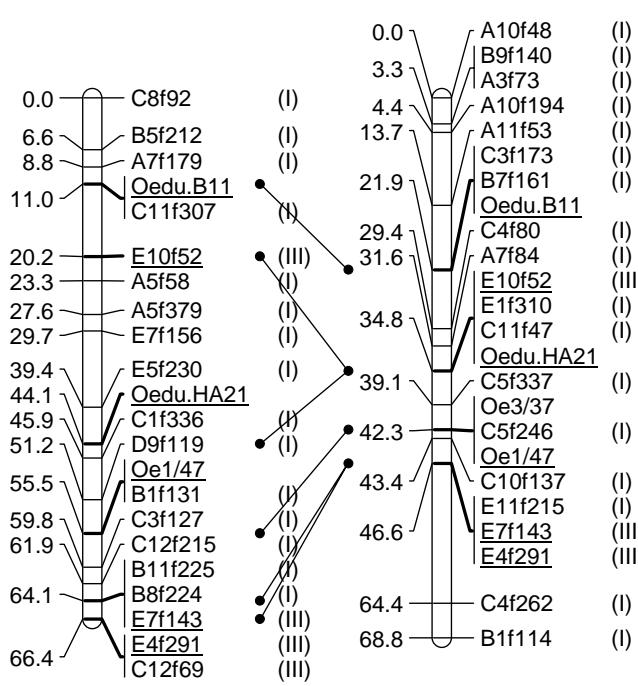

P2_11

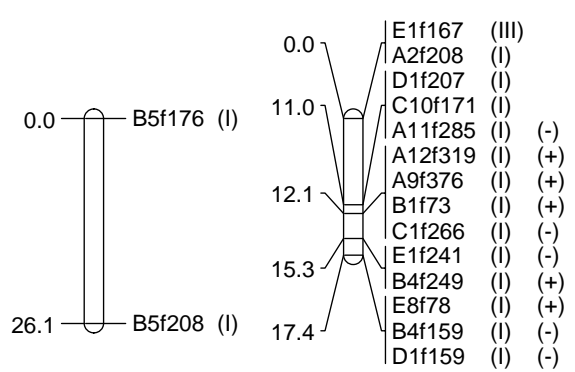




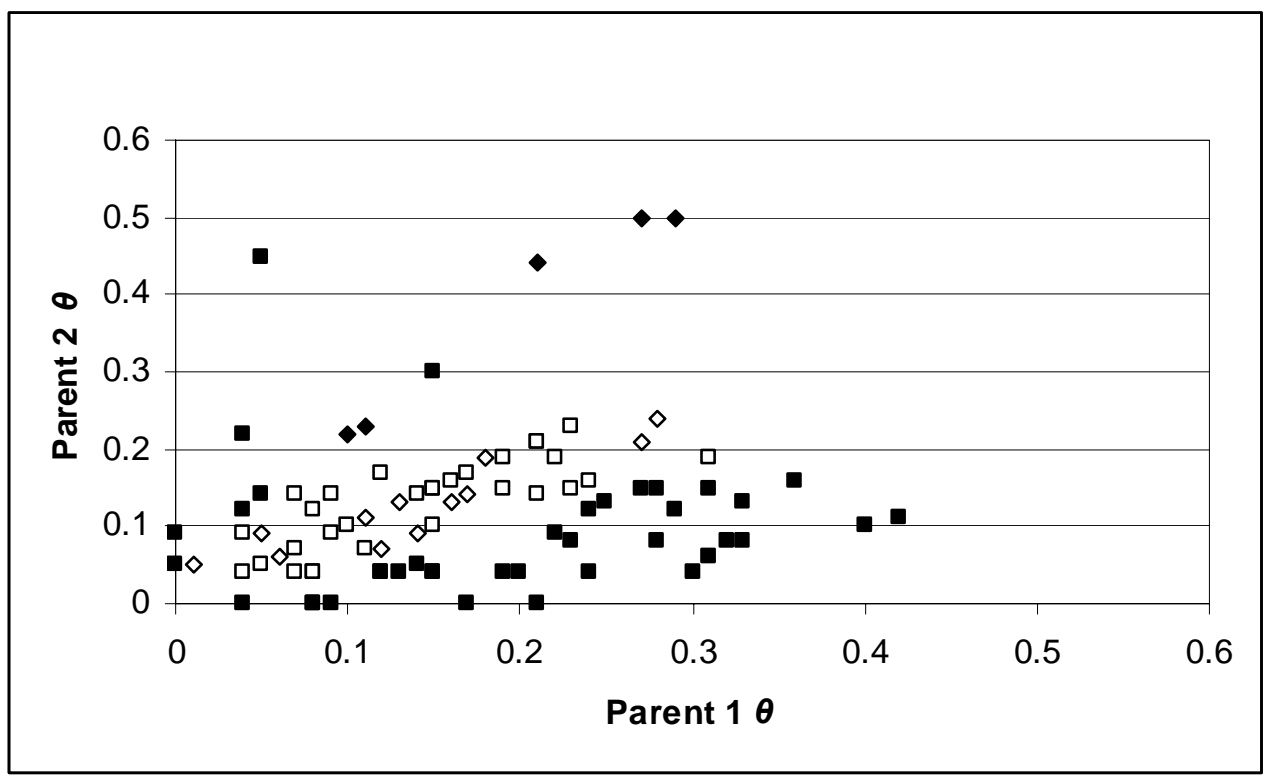

